\title{
Anesthesia in Bariatric Surgery: The Twelve Labors of Hercules?
}

\author{
Marcel de Quelerij and Serge JC Verbrugge* \\ Franciscus ziekenhuis, locatie Gasthuis, Kleiweg 500,3045 PM Rotterdam, The Netherlands
}

Received: October 28, 2015; Accepted: December 15, 2015; Published: December 26, 2015

*Corresponding author: Serge JC Verbrugge, Franciscus ziekenhuis, locatie Gasthuis, Kleiweg 500,3045 PM Rotterdam, The Netherlands, 00-31-104616161: E-mail: s.verbrugge@franciscus.nl

Keywords: Bariatric surgery; Anesthesia; Complications; Protocol

In Greek mythology, the twelve labors refer to a series of tasks carried out by Hercules, the greatest of Greek heroes, accomplished over a twelve year period [1, 2]. Anesthetizing bariatric patients may unfairly feel like Herculean penances to the anesthesiologist. In this short editorial, we want to summarize what we have learned from a 12 year (2004-2015) anesthetic experience with this category of patients in our teaching hospital, specified to uncomplicated endoscopic gastric sleeve-and bypass procedures and how we feel anesthesia should be performed in this group.

Numerous peri-operative anesthetic problems related to bariatric surgical patients have been described and include e.g. 1) difficult to control diabetes, 2) asthma, 3) unhealthy lifestyle and smoking habits [3], 4) sleep apnea, 5) cardiac problems, 6) difficulties with mask ventilation and 7) intubation, 8) ventilatory problems, 9) uncertainty about the exact pharmacokinetics and 10) Pharmacodynamics, 11) risk of thromboembolic complications and 12) the risk of postoperative airway obstruction when opioids are given to this group of patients [4].

In addition to an Enhanced Recovery after Bariatric Surgery (ERABS) protocol our current standardized anesthetic regimen in Bariatric surgery has been extensively described elsewhere [5]. In short, it is based on a couple of pillars. 1) We give no sedative premedication. 2) Patients are instructed to make their own transfer from the bed to the operating table and back before and after anesthesia. 3)The patient is positioned on a special cushion in a Head Elevated Laryngoscopy Position (HELP) as described elsewhere [6] to maximize sniffing position and facilitate mask ventilation and also 4) intubating conditions, which are also facilitated by using a laryngoscope with a short handle and a stylet. 5) All patients are ventilated in a pressure controlled mode with PEEP settings (minimal PEEP level of $8 \mathrm{~cm} \mathrm{H}_{2} \mathrm{O}$ ) assuring a saturation $>95 \%$ at $40 \% \mathrm{FiO}_{2}$ and a minute ventilation (tidal volume $\mathrm{x}$ ventilator frequency) to assure an end tidal $\mathrm{CO}_{2}<40$ $\mathrm{mmHg}$ at high ventilator frequencies with peak pressure < $30 \mathrm{cmH}_{2} \mathrm{O}$ if possible. 6) Peri-operatively we use short acting anesthetic agents (desflurane and remifentanil) and 7) for muscle relaxation rocuroniumbromide antagonized with sugammadex at the end of the operation [7]. While others endorse the use of dexmedetomidine and avoidance of opioids in this patient group [8], 8) we have good experience with regular opioids and ketamine after induction of anesthesia; 9) in the recovery room we titrate regular opioids combined with clonidine, meperidine and intravenous acetaminophen to a VAS score of $<4$ before the patient is dismissed from the recovery room. 10) We give little if any opioids on the wards where 11) the main pillar of ERABS is early mobilization within 2 hours postoperatively under the supervision of a physiotherapist.

When we began with bariatric surgery in our hospital we used to admit patients with identified risk factors (such as e.g. the superobese (BMI > 50), documented sleep apneas with CPAP, difficult to regulate diabetes and documented pulmonary hypertension) to the ICU for a 24 hours postoperative surveillance. We found however, 12) that admittance to the ICU has no additional value and does only result in late mobilization and may thereby increase the risk of thromboembolism [9].

In table 1 we have shown the number of uncomplicated endoscopic gastric [10] sleeve and bypass procedures from 2004-august 2015 with the average time in the operating theatre (TOT) for both procedures. Endoscopic gastric bypasses where only performed starting from 2008. The total number of procedures for 2015 is not depicted as the year was not completed yet during the writing of this editorial; the average time for 2015 up to august is depicted. Our ERABS anesthesia protocol contributed to a reduction in TOT for endoscopic gastric sleeves from 162 to 59 minutes from 2004 to 2015 and for endoscopic gastric bypass surgery from 236 to 77 minutes from 2008 to 2015 (Table 1) [5]. This was achieved without a difference in the amount of anesthesia related complications.

In summary, the anesthesiologist does not have to introduce Herculean measures to properly care for the bariatric patient. Airway and ventilatory management is not the Nemian lion where properly prepared; pharmacokinetics and dynamics using a standard protocol are not as mystical as the Stymphalian birds and peri operative care and organization do not represent an Ermanthian Boar if the key strategy is early mobilization of the patient. 
Table 1: Number of Endoscopic Gastric sleeve and Gastric bypass procedures with average Time in the Operating Theatre (TOT) in our hospital from 2004-2015.

\begin{tabular}{|c|c|c|c|c|}
\hline & Endoscopic Gastric Sleeve & & Endoscopic Gastric Bypass & \\
\hline Year & Number $(n)$ & Average TOT (min) & Number (n) & Average TOT (min) \\
\hline 2004 & 9 & 162 & & \\
\hline 2005 & 31 & 154 & & \\
\hline 2006 & 30 & 156 & & \\
\hline 2007 & 44 & 157 & & \\
\hline 2008 & 63 & 131 & 2 & 236 \\
\hline 2009 & 167 & 208 & 25 & 224 \\
\hline 2010 & 179 & 85 & 34 & 149 \\
\hline 2011 & 238 & 65 & 206 & 96 \\
\hline 2012 & 261 & 64 & 214 & 92 \\
\hline 2013 & 203 & 62 & 319 & 79 \\
\hline 2014 & 291 & 62 & 294 & 79 \\
\hline $2015^{*}$ & 133 & 59 & 190 & 77 \\
\hline
\end{tabular}

\section{References}

1. (Pseudo-) Apollodorus. The Library (in Greek). With an English Translation by Sir James George Frazer, F.B.A., F.R.S. in 2 Volumes. London: Harvard University Press; William Heinemann Ltd. At the Perseus Project. 1921.

2. Isocrates. "1.8”. Isocrates (in Greek). With an English Translation in three volumes, by George Norlin, Ph.D., LL.D. Cambridge, MA; London: Harvard University Press; William Heinemann Ltd. At the Perseus Project.

3. Haritha J, Wilcox CM. Evaluation of Patients' Knowledge Regarding Smoking and Chronic Pancreatitis: A Pilot Study. J Gastroenterol Pancreatol Liver Disord. 2015;1(2):1-4.

4. Proczko MA, Stepaniak PS, de Quelerij M, van der Lely FH, Smulders JF, Kaska L, et al. STOP-Bang and the effect on patient outcome and length of hospital stay when patients are not using continuous positive airway pressure. J Anesth. 2014;28(6):891-897. doi: 10.1007/ s00540-014-1848-0.

5. Mannaerts GH, van Mill SR, Stepaniak PS, Dunkelgrun M, de Quelerij $\mathrm{M}$, Zengerink HF, et al. Results of Implementing an Enhanced Recovery after Bariatric surgery (ERABS) protocol. Obes Surg . 2016;26(2):303312. doi: $10.1007 / \mathrm{s} 11695-015-1742-3$.

6. Brodsky JB, Lemmens HJM, Brock-Utne JG. Morbid obesity and tracheal intubation. Anesth Analg 2002;94(3):732-736.

7. Carron M, Veronese S, Foletto M, Ori C. Sugammadex allows fast-track bariatric surgery. Obes Surg. 2013;23(10):1558-1563. doi: 10.1007/ s11695-013-0926-y.

8. Ziemann-Gimmel P, Goldfarb AA, Koppman J, Marema RT. Opioidfree Total intravenous anesthesia reduces postoperative nausea and vomiting in bariatric surgery beyond triple prophylaxis. Br J Anaesth. 2014;112(5):906-911. doi: 10.1093/bja/aet551.

9. de Quelerij M, van Velzen C, Luitwieler R, Meijer N, Gadiot RPM, van der Voet J, et al. Prevelance and determinants of complications in a bariatric ICU population. Nederlands Tijdschrift voor Anesthesiologie, december 2012;16-21.

10. Nakagawa K, Koike T, Katsunorilijima, Ohara S, Hamada S, et al. Outcomes after GERD Treatment Based on the Japanese GERD Management Guideline. Gastroenterol Pancreatol Liver Disord. 2015; 2(2): $1-8$ 